\title{
Abdomen and thorax clinical anatomy: from viscera morphology and vascularization to epidural and caudal anesthetic techniques
}

\author{
Fabrice Duparc ${ }^{1}$ (D) $\cdot$ Bruno Grignon ${ }^{2}$
}

Published online: 24 August 2021

(c) The Author(s), under exclusive licence to Springer-Verlag France SAS, part of Springer Nature 2021

The submitted manuscripts concerning the clinical anatomy of the abdomen and thorax are less numerous than the works devoted to other regions of the human body. We are happy to bring together in this issue articles on these parts of the trunk.

The contribution to the liver anatomy of Francis Kiernan, surgeon and anatomist, is emphasized and completes interestingly the special issue "The anatomy of the liver: from Couinaud to the transplantation" that was published in Surg Radiol Anat on December 2020.

The morphology of the pancreas has been revisited on MDCT, with important clinical relevance in surgical practice, and these aspects of the gland are enriched by a study about the prepancreatic common hepatic artery and two other articles about variations of arteries but also portal vein.

A study of the impact of age and gender on the colorectal dimensions is reported, and an original aspect related to the complete common mesentery is presented with agenesis of the areas of junction of the colon with the posterior wall.

The retroperitoneal space is also present in this issue through too studies about the iliac venous variations and arterial renal anatomy, respectively.
The abdominal cavity is surrounded by muscular limits that can show some variations of importance for the surgeons and radiologists.

Going through the diaphragm, this issue is completed by the anatomical variations of the inferior phrenic artery, a large study of the thoracic duct in pediatric surgery, and particular aspects of vertebral arteries origins and of the right pulmonary vein.

Finally, as the spine represents the axis of the trunk, with close relations to the medulla and roots, we associated four articles of great interest in the field of the anatomical basis of anesthesiology techniques, epidural injections and sacral hiatus parameters for caudal injections.

We wish you an interesting reading.

Publisher's Note Springer Nature remains neutral with regard to jurisdictional claims in published maps and institutional affiliations.
Fabrice Duparc

fabrice.duparc@univ-rouen.fr

Bruno Grignon

b.grignon@chu-nancy.fr

1 Department of Anatomy, Faculty of Medicine-Pharmacy, University of Rouen-Normandy, 22 Boulevard Gambetta, 76183 Rouen, France

2 Department of Anatomy, Faculty of Medicine, University of Lorraine, Avenue de la Forêt de Haye, 54505 Vandœuvre-lès-Nancy, France 